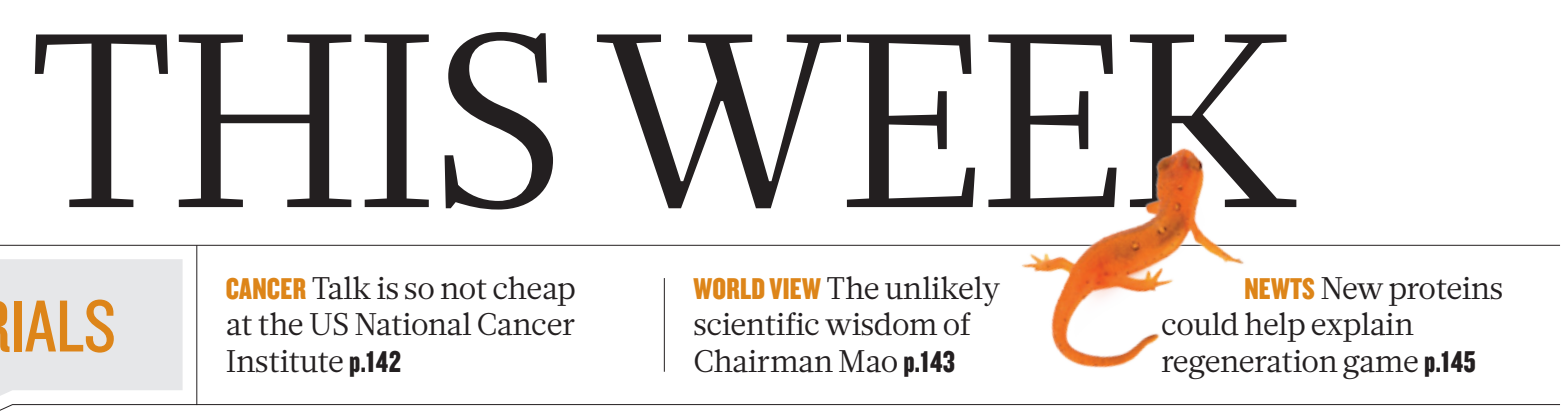

\title{
The antibiotic alarm
}

\author{
There is a growing recognition that action must be taken to deal with the alarming rise in the \\ incidence of bacteria resistant to today's antibiotics, and its implications for global health.
}

$\mathrm{T}$ The threat posed by the spread of antibiotic-resistant strains of bacteria is unlikely to be news to Nature's readers. Stories of the spread of 'superbugs' have become familiar in recent years. Yet what may come as more of a surprise is the relatively low level of recognition that this problem has received among policy-makers, especially when compared with the potentially catastrophic nature of the crisis that is unfolding. In essence, we are engaged in an arms race with pathogenic bacteria - and we are losing.

Academics, health-care professionals and campaigners have for decades warned that the misuse and over-prescription of antibiotics have led to a rise in resistant strains, a problem compounded by an alarming decline in the discovery and development of new classes of antibiotic. However, that message has grown stronger in recent years, and the previously disparate voices have begun to shout as one. Wellorganized campaigns such as Antibiotic Action (a global initiative of the British Society for Antimicrobial Chemotherapy) have applied important pressure and raised the profile of the antibiotic-resistance threat with policy-makers around the world. At last, there are signs that the message is being heard.

This week saw the launch of a UK report into infections and the rise of antimicrobial resistance from Sally Davies, the UK chief medical officer. The report draws on the expertise of academics and health-care professionals to outline the burden of infectious disease in the United Kingdom and the increasing proportion of infections due to antibiotic-resistant strains. Davies makes 17 recommendations for policy and political action relating to antibiotic resistance, pathogen surveillance, prevention of infection and training for the health-care workforce. Chief among these recommendations is that antibiotic resistance should be added to the UK government's list of threats to national security, alongside pandemic influenza and terrorism, a recommendation alone that is sure to raise the profile of the issue. Importantly, Davies' report also recognizes the global nature of the challenge posed by antibiotic resistance and calls for international leadership and coordinated action. The report precedes the upcoming announcement of the UK cross-government antimicrobial-resistance strategy for 2013-18, which is supposed to make these things happen.

The call for better surveillance, better training for health-care professionals and more prudent use of antibiotics is also reflected in a second report, which was published on 5 March by the US Centers for Disease Control and Prevention and focused specifically on infections with carbapenem-resistant Enterobacteriaceae (CRE). Carbapenems are among the last options for treating many bacterial infections, and the increasing prevalence of CRE infections in the United States in the past decade is of concern, especially given that such infections are most often associated with patients undergoing serious medical procedures.

There have been many false dawns in the fight to raise the profile of antibiotic resistance and introduce meaningful policy changes.

Despite expert advice to the contrary, antibiotics remain heavily overprescribed by doctors around the world. In many countries they are available to buy over the counter without a prescription. In addition, in both the developed and the developing world, antibiotics remain in wide use as growth supplements in livestock, a practice that has drawn much criticism.

As the recent reports show, politicians and policy-makers are beginning to pay the antibiotic issue greater attention, and scientists should

\section{"Antibiotics} remain heavily over-prescribed by doctors around the world." als and policy-makers, as well as representato draw up a plan to tackle the crisis together. This will not be an easy process, and in addition to meaningful political will, it will probably require substantial funding. In the current global financial climate, this is likely to be a sticking point. But the potential financial and human cost of not tackling this crisis will almost certainly be much greater. It was not that long ago that loss of a sibling to a now-treatable disease was a common occurrence in Britain. We must not turn the clock back.

\section{Form and function}

\section{Although debate over scientific definitions is important, it risks obscuring the real issues.}

0 cience is at the mercy of its language. It can be difficult for researchers to communicate what most excites them about the beauty, intricacy and complexity of the natural world. And when words fail, debates and arguments often arise.

One enduring debate has been resurrected by ENCODE, the Encyclopedia of DNA Elements - an ongoing multimillion-dollar project to catalogue the functional elements of the human genome. A headline-grabbing claim, first made in this publication last September, was that roughly $80 \%$ of human DNA had been ascribed some "biochemical function" thanks to the efforts of more than 440 scientists (The ENCODE Project Consortium Nature 489, 57-74; 2012).

That percentage is remarkably high, in part because of a broad definition of 'function'. The ENCODE team used the term to include binding by a regulatory protein, or transcription into RNA - activities 